\title{
Om begrepet håp
}

\author{
Ved Henning Herrestad
}

Hva innebærer det å ha et håp og å være håpefull? I denne artikkelen søker vi å belyse hvordan man forstår begrepet håp og hvordan man har studert håp i filosofi og empirisk forskning. Hensikten er å inspirere til videre suicidologiske studier av håp samt å gi klinikere som snakker om håp med sine pasienter, forståelse for de ulike aspektene ved håp. En viktig innsikt om håp er at først når mål i framtiden blir usikre dukker håpet opp, og sammen med håpet frykt for skuffelse. Den beste hjelp for å styrke håpet og unngå skuffelse er tiltak som kan redusere usikkerheten, som å gi forståelse for hva man selv kan gjøre for å nå målet.

Er det en viktig oppgave for helsepersonell å prøve å vekke håp hos pasienter med selvmordsatferd? Det er god evidens for at høy grad av håpløshet innebærer en høy risiko for selvmord (Beck, 1986), men dette betyr ikke uten videre at det å vekke håp kan løse problemene. En ny forskningsgjennomgang av betydningen av håp for psykisk helse viser at det er vanlig å anse håp som en viktig terapeutisk faktor, men at det ikke finnes god evidens for hva dette betyr i praksis eller noen utbredt enighet om hva begrepet håp innebærer (Schrank et al., 2008). Her skal det først og fremst handle om håp, og det er ikke plass til å behandle håpløshet og faktorer som medvirker til opplevelser av håpløshet på noen fyllestgjørende måte. Artikkelen er et fors $\varnothing \mathrm{k}$ på å bidra til en klargjøring av begrepet håp i lys av filosofisk begrepsanalyse og av bruken av begrepet i empirisk forskning. Før vi kan gi noe svar på om det er en terapeutisk oppgave å vekke håp, må vi kunne si noe om hva det innebærer å ha håp.

\section{Filosofiske analyser av begrepet håp}

La oss ta utgangspunkt i J. P. Days filosofiske analyse av begrepet håp (Day, 1991). I følge Day er middelalderfilosofen Thomas Aquinas' definisjonen av håp den mest kjente:

"Hope is a movement of appetite aroused by the perception of what is agreeable, future, arduous, and possible of attainment."

"Håp er en bevegelse av viljen vekket av oppfatningen av hva som er tiltalende, fremtidig, anstrengende og mulig å oppnå" (min oversettelse).

Håp innebærer altså at man vil at noe skal bli virkelig, noe som impliserer at denne tilstanden er $\varnothing$ nskelig. Day påpeker at når Aquinas inkluderer "anstrengende", er det for å utelukke tilstander man regner med at sikkert vil inntreffe eller regner som selvfølgelige. Jeg håper at gulvet vil bære meg kun når jeg har grunn for å tro at det kanskje ikke vil gjøre det. Day tolker det at tilstanden må være mulig å oppnå som at man selv må tro det er et minimum av sannsynlighet for at tilstanden vil bli virkelig. Jeg kan håpe at det vil regne i natt selv om ikke jeg selv kan gjøre noe for å oppnå dette.

1700-tallsfilosofen David Hume anså håp i seg selv for å være en følelse. Han skriver at følelsene frykt og håp er blandinger av smerte og nytelse. Når et gode er sikkert, vekkes nytelse. Når et onde er sikkert, vekkes smerte. Når et gode eller onde er usikkert, vekkes blandinger av smerte og nytelse. Når blandingen har en overvekt av nytelse kaller vi det håp, når blandingen har en overvekt av smerte kaller vi det frykt. En person kan svinge fram og tilbake mellom frykt og håp. Om han ser det som usannsynlig at det vil bli slik han $\varnothing$ nsker, kan han kjenne frykt. Men om han tror sannsynligheten $\varnothing$ ker, fatter han nytt håp. Ifølge Day tar Hume feil nå han hevder at håp og frykt er følelser, men de involverer følelser av nytelse og smerte.

Det å snakke om å håpe eller ha håp uten å spesifisere om hva, er i følge Day det samme som å si at man har et håp med et ubestemt objekt. Tilsvarende kan det å være håpefull innebære en generell holdning som ikke trenger å ha noe spesifikt objekt. En håpefull holdning innebærer å tolke det som skjer på en positiv måte, for eksempel å se et glass som halvt fullt framfor som halvt tomt. Day kobler det å ha håp med ubestemte objekter og det å være håpefull til det vi kaller optimisme.

\section{Bruken av begrepet håp i empirisk forskning}

I sin gjennomgang av forskning som omhandler begrepet håp, instrumenter for måling av håp og forskning på håp hos pasienter i psykisk helsevern fant Schrank et.al. (2008) 49 ulike definisjoner av håp, 32 ulike instrumenter for måling av håp og 11 studier av håp. Her gjengis deres definisjon av håp fordi den er en syntese og oppsummering av de 49 definisjonene av begrepet håp:

“... we define hope as primarily future oriented expectation (sometimes but not always informed by negative experiences such as mental illness) of attaining personally valued goals, relationships or spirituality, where attainment:

i) will give meaning,

ii) is subjectively considered realistic or possible and

iii) depends on personal activity or characteristics (e.g. resilience and courage) or external factors (e.g. resources available).

Hope comprises four components: affective (e.g. trust, confidence, humour and positive emotions); cognitive

(e.g. reflecting on past experiences, goalsetting, planning and assessing the likelihood of success); behavioural (e.g. motivation and personal activity); and environmental (e.g. availability of resources, health care and relationships)." (Schrank et al., 2008, s. 426)

Denne definisjonen er mindre elegant enn definisjonen til Aquinas, og den tilføyer egentlig ikke så mye. For eksempel er det vel tautologisk å si at oppfyllelsen av håpet enten avhenger av egen innsats eller av eksterne faktorer. Men oppsummeringen av håpets fire komponenter tilføyer noe nytt, og i den videre framstillingen vil vi unders $\varnothing$ ke hvordan håp 
involverer følelser og hvordan håp involverer omgivelsene. Hvordan håp involverer kognisjon og handling, vil vi unders $\varnothing$ ke under ett. At disse dimensjonene er vanskelige å skille antydes av at definisjonen av atferd inkluderer motivasjon, som vi ser som en mental st $\varnothing$ rrelse. Vi vil dessuten unders $\varnothing$ ke nærmere hva det innebærer at håp ofte er inspirert av negative erfaringer.

\section{Håp involverer følelser}

I en mye sitert kvalitativ unders $\varnothing$ kelse av håp hos alvorlig syke og døende pasienter skriver Dufault \& Martocchio (1985):

"The affective dimension permeates the whole of the hoping process. It encompasses multiple feelings, both comforting and painful. ... Individuals' confidence and uncertainty about the outcomes of hope objects fluctuates, as does their feelings about their attraction to and the personal significance of hope objects." (Dufault \& Martocchio, 1985, s. 384).

Lohne og Severinsson står bak en serie studier av håp hos pasienter med ryggmargskader der vekslende følelser står sentralt (oppsummert i Lohne, 2008). Lohne beskriver hvordan disse pasientene pendler mellom fortvilelse over sin situasjon og håp om å gjenvinne førlighet, i hennes analyse en kamp mellom lidelse og håp. I hennes modell av håp leder fortvilelsen til døden, mens håpet leder til liv gjennom forsoning og personlig vekst. En rimelig tolkning av hennes modell kan være at disse pasientene hadde selvmordstanker da de var fortvilet, og så for seg at de kunne tatt sitt eget liv om fortvilelsen hadde vedvart, men at det å ha håp dempet selvmordstankene deres.

Ifølge Day (1991) var både grekerne og romerne ambivalente i forhold til om håp var et gode nettopp fordi å håpe kan gi smerten over å bli skuffet. Et uttrykk for dette er myten om Pandoras eske. Pandora åpnet esken, og ut slapp all verdens plager som sorg, sykdom og ufred, personifisert som ånder. Forgjeves fors $\varnothing$ kte hun å slå lokket igjen, men ikke helt forgjeves. Håpets ånd ble holdt tilbake i esken.

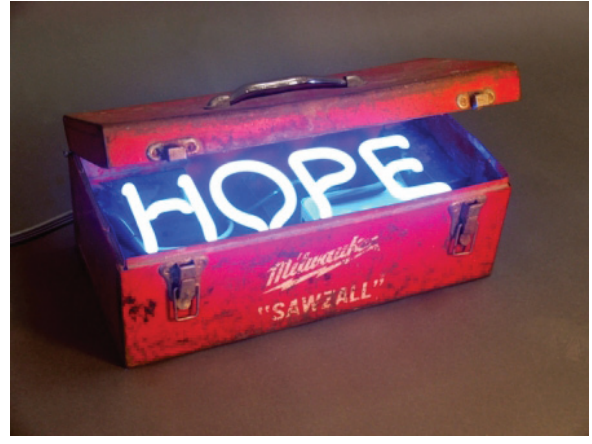

Dette kan tolkes som at håp er en motgift mot alle andre plager, eller som at håp også er en plage fordi det hindrer mennesket i å avfinne seg med situasjonen det er i. Spesielt de stoiske filosofene advarer mot håp. For dem var indre ro, såkalt "stoisk ro”, det eneste gode verdt å søke. De advarte mot håp fordi de ser både glede og smerte som indre uro.

Pasientene Lohne (2008) intervjuet hadde alle beveget seg fra å være tynget av fortvilelse, via et vendepunkt der håpet fikk overtaket, fra en eksistens i fortvilelse til en eksistens i håp. De beskriver håpets kilde som lengselen etter å leve slik de gjorde $f \varnothing r$ de fikk skaden. Minnet om gode tider var altså viktig for å generere håp. Mens håpet særlig var knyttet til forbedret førlighet i begynnelsen av rehabiliteringsprosessen, skiftet det til et håp om å ha en god tilværelse etter 3-4 år. For disse pasientene var altså håpet en kilde til forsoning mer enn en kilde til indre uro og skuffelse fordi håpet etter hvert skiftet innhold. Men dette skjedde gjennom en form for indre kamp med sterke og vekslende følelser.

\section{Håp involverer kognisjon og handling}

Schrank et al. (2008) beskrev håp som en forventning om noe en person anser for realistisk eller mulig å oppnå. I følge Dufault \& Martocchio (1985) skiller dette håp fra $\varnothing$ nsker, for vi kan godt $\varnothing$ nske oss det umulige. $\AA$ anse noe som mulig kan, i tråd med Days tolkning av Aquinas, innebære at man tror det er en viss sannsynlighet for at dette kan bli virkelig, enten det nå er som en følge av naturlige prosesser eller av andres handlinger. $\AA$ dertil tro at man selv kan påvirke realiseringen av håpet er en enda sterkere form for håp, fordi et slikt håp gir motivasjon for planlegging og handling.
Psykologen C.R. Snyder (1994, 2000a) har utviklet en kognitiv psykologisk teori om håp som vektlegger at håp gir motivasjon. Snyder gir følgende definisjon av håp:

"Hope is a positive motivational state that is based on an interactively derived sense of successful (a) agency (goaldirected energy), and (b) pathways (planning to meet goals)"

\section{(Snyder, 2002).}

Denne definisjonen av håp vektlegger at håp er en mental tilstand som forutsetter at man i samspill med andre (interactively derived) har fått utviklet en forestilling om at man har evne til å nå mål gjennom egen målrettet handling (Snyder, 2000a). Videre forutsetter håp at man har en evne til å planlegge en vei til å nå målet, hvilket Snyder kaller pathways thinking (Snyder, 2000b).

Snyders definisjon er snevrere enn dem vi alt har nevnt, for den utelukker at man kan ha håp om ting man ikke selv kan influere på. Snyder (2002) har utviklet en rekke instrumenter for måling av håp med gode psykometriske egenskaper, disse er blant de mest brukte instrumentene for måling av håp i relasjon til psykisk helse (Schrank et al., 2008). (Ill. 1 på neste side viser ett av disse instrumentene: The State Hope Scale.) Men ingen av studiene der Snyders instrumenter er brukt, omhandler selvmordsproblematikk. En mindre klinisk unders $\varnothing$ kelse viser at pasienter innlagt for parasuicid hadde like mange positive livsmål som pasienter som var innlagt for ulykker, men at pasientene innlagt for parasuicid så for seg færre veier mot disse målene (Vincent et al., 2004). Dette kan innebære at suicidale personer har dårlig evne til planlegging.

Snyder (1994, s. 150) har en hypotese om utviklingen av selvmordsatferd: Opplevelsen av å mislykkes i å nå viktige livsmål gir sterke følelser av smerte og frustrasjon. Enkelte personer ser døden som en måte å unngå disse følelsene på, og de gjør døden til et mulig mål. De gjør $\mathrm{d} \varnothing \mathrm{den}$ til et håp gjennom å se $\mathrm{d} \varnothing$ den som innen rekkevidde av egen handling (agency) og ved å se for seg mulige veier (pathways) til å ta sitt eget liv. Snyder kaller retorisk selvmord the final act of hope. 


\section{Illustrasjon 1: The State Hope Scale}

Directions: Read each item carefully. Using the scale shown below, please select the number that best describes how you think about yourself right now and put the number in the blank before each sentence. Please take a few moments to focus on yourself and what is going on in your life at this moment. Once you have this "here and now" set, go ahead and answer each item according to the following scale:

\begin{tabular}{c|c|c|c|c|c|c|c}
\hline $\begin{array}{c}\text { Definitely } \\
\text { False }\end{array}$ & $\begin{array}{c}2=\text { Mostly } \\
\text { False }\end{array}$ & $\begin{array}{c}3=\text { Somewhat } \\
\text { False }\end{array}$ & $\begin{array}{c}4=\text { Slightly } \\
\text { False }\end{array}$ & $\begin{array}{c}5=\text { Slightly } \\
\text { True }\end{array}$ & $\begin{array}{c}\text { Somewhat } \\
\text { True }\end{array}$ & $\begin{array}{c}\text { Some Mostly } \\
\text { True }\end{array}$ & $\begin{array}{c}8=\text { Definitely } \\
\text { True }\end{array}$ \\
\hline
\end{tabular}

1. If I should find myself in a jam, I could think of many ways to get out of it.

2. At the present time, I am energetically pursuing my goals.

3. There are lots of ways around any problem that I am facing now.

4. Right now, I see myself as being pretty successful.

5. I can think of many ways to reach my present goals.

6. At this time, I am meeting the goals that I have set for myself.

Source: Snyder, C. R. Hope theory: Rainbows in the mind. Psychological Inquiry, 13, 249-275. - Jan 1,2002 . Reprinted by permission of the publisher (Taylor \& Francis Group, http://www.informaworld.com).

Denne teorien er foreslått som en ny innfallsvinkel til suicidologisk forskning (Grewal \& Porter, 2007). Men den passer antagelig bedre som forklaring på planlagte selvmord enn på impulsive selvmordshandlinger, for impulsive selvmordshandlinger synes å kunne skje uten en slik motivasjon (Oquendo \& Mann, 2000). Håpløshet målt med Becks håpløshetsskala (BHS) er grundig studert som en viktig mediator mellom depresjon og selvmordstanker og en prediktor for selvmord (Beck et al., 1974; Beck, 1986). BHS har vist god sensitivitet (den fanger opp de fleste med høy grad av håpløshet), og den er i utstrakt bruk (Glanz et al., 1995). I sin faktoranalyse fant Beck at spørsmålene i BHS dreide seg tre temaer: Om følelser i forhold til framtiden (e.g. "My future seems dark to me"), om tap av motivasjon (e.g. "There is no use in really trying to get something I want because I probably won't get it") og om fremtidige forventninger (e.g. "All I can see ahead of me is unpleasantness rather than pleasantness") (Beck et al., 1974). Snyders definisjon gjør håp til en faktor som $\varnothing$ ker motivasjon, mens definisjonen til Schrank et al. (2008) kan operasjonaliseres til å fange både motivasjon og fremtidige forventninger. I tråd med dette $\varnothing$ nsket om å fange flere aspekter ved håp foreslår Schrank et al. at man bruker både Snyders State Hope Scale og Herth Hope Index (se illustrasjon 2) for måling av håp i klinisk arbeid.
I forskningen om depressive lidelser har man særlig knyttet håpløshet til den første av BHS-faktorene, dvs. til en manglende evne til å se for seg positive fremtidige hendelser. En slik manglende evne knyttes til problemer med å hente opp spesifikke minner om tidligere hendelser (såkalt overgenerelt minne) (Williams, 2001). I en serie unders $\varnothing$ kelser har MacLeod og hans medarbeidere (MacLeod et al., 1993, 1997, 2005) funnet at håpløshet hos personer som har skadet seg selv (parasuicide) ikke er knyttet til forventninger om negative fremtidige hend-

\begin{tabular}{|c|c|c|c|c|}
\hline Illustrasjon 2: Herths håpindeks & $\begin{array}{l}\text { Veldig } \\
\text { uenig }\end{array}$ & Uenig & Enig & $\begin{array}{l}\text { Veldig } \\
\text { enig }\end{array}$ \\
\hline \multicolumn{5}{|l|}{ 1. Jeg ser positivt på livet } \\
\hline \multicolumn{5}{|l|}{ 2. Jeg har kort- og/eller langsiktige mål } \\
\hline \multicolumn{5}{|l|}{ 3. Jeg føler meg helt alene } \\
\hline \multicolumn{5}{|l|}{ 4. Jeg ser lys i tunnelen } \\
\hline \multicolumn{5}{|l|}{ 5. Jeg har en tro som gir meg trøst } \\
\hline \multicolumn{5}{|l|}{ 6. Jeg er redd for hva fremtiden vil bringe } \\
\hline \multicolumn{5}{|l|}{ 7. Jeg kan huske lykkelige/gode stunder } \\
\hline \multicolumn{5}{|l|}{ 8. Jeg har en indre styrke } \\
\hline \multicolumn{5}{|l|}{ 9. Jeg er i stand til å gi og motta omsorg/kjærlighet } \\
\hline \multicolumn{5}{|l|}{ 10. Jeg har en følelse av retning i livet mitt } \\
\hline \multicolumn{5}{|l|}{ 11. Jeg tror at hver dag har sine muligheter } \\
\hline 12. Jeg føler at mitt liv har verdi & & & & \\
\hline
\end{tabular}

Kilde: Rustoen, T. Endrer håpet seg med diagnoser? Omsorg - Nordisk tidsskrift for palliativ medisin, 2008, 25, 7-11. elser, men til mangel på forventning om positive hendelser. Williams (2001) kobler en slik opplevelse av håpløshet til selvmordsatferd gjennom teorien om at manglende evne til å se for seg framtidige positive hendelser gir personen en opplevelse av å være fanget i en negativ nåsituasjon. Lohne (2008) finner det samme. Hun påpeker at for hennes pasienter er fortiden viktig for håp ved at gode minner gir grunnlag for håp om å gjenoppleve lignende opplevelser (Lohne, 2008), og dette poenget er inkludert i enkelte definisjoner av håp (Schrank et al., 2008).

\section{Håp involverer omgivelsene - spesielt andre mennesker}

Pasientene som Dufault \& Martocchio (1985) intervjuet, formidlet at håp involverte andre enn dem selv på flere ulike måter. Pasientene uttrykte håp om gode relasjoner til andre mennesker eller ting (levende, døde, dyr, krefter, Gud). De uttrykte at realiseringen av deres håp var avhengig av andres handlinger og st $\varnothing t t e$, og de uttrykte at deres håpefullhet var avhengig av at andre delte deres håp. Igjen er det relevant å trekke inn teorier om håpløshet. Melges og Bowlby (1969) skriver at personer som opplever liten tilknytning til andre mennesker, vil ha liten tillit til at andre mennesker vil hjelpe dem med å nå sine mål. De vil også lett oppleve å være utestengt fra muligheter som gis andre (Melges \& Bowlby, 1969). 
Dette gir en mer relasjonell forståelse av håpløshet som en opplevelse av å være sosialt utestengt.

I en serie kvalitative studier av sykepleieres rolle i behandlingen av suicidale pasienter har John R. Cutcliffe og medarbeidere satt fokus på betydningen av relasjonen mellom sykepleier og pasient som kilde til håp hos pasienten (Cutcliffe $\&$ Barker, 2002; Collins \& Cutcliffe, 2003; Cutcliffe et al., 2007). I den siste studien fant de at deltagerne gjennomgående beskrev en følelse av disconnection from humanity, og at den psykiatriske sykepleieren gjorde det mulig for dem å tilkoble seg igjen gjennom å være en varm, omsorgsfull representant for menneskeheten som pasientene fikk tillit til.

\section{Øker håp gjennom negative erfaringer?}

Dufault \& Martocchio (1985, s. 388) skriver: "A frequent context within which hope is experienced is the situation of actual or potential loss.".

At situasjoner med faktiske eller potensielle tap faktisk kan $\varnothing$ ke en persons håpefullhet illustreres i Rustøens forskning på håp hos alvorlig syke pasienter; pasienter med hjertesvikt (Rustoen et al., 2005), cystisk-fibrose (Rustoen et al., 2004) og kreftsyke pasienter under smertebehandling (Rustoen, 2008). I denne forskningen ble den norske versjonen av Herth Hope Index brukt (se illustrasjon 2). Dette er et instrument utviklet for å kunne måle graden av håpefullhet hos pasienter i en klinisk hverdag, og det er basert på Dufault \& Martocchios analyse av begrepet håp (Herth, 1992).

Rustøen (2008) oppsummerer sine funn med å påpeke det uventede $\mathrm{i}$ at de alvorlig syke pasientgruppene hadde høyere global håpsskåre enn normalbefolkningen. Dette er helt i tråd med Days kommentar nevnt ovenfor om at vi ikke har håp om det vi tar for gitt. Når god helse ikke lenger tas for gitt, begynner vi å håpe på den. Når en dag uten smerte ikke lenger tas for gitt, vekkes et håp om en slik dag.

\section{Håp, håpefullhet og optimisme}

Dufault \& Martocchio (1985, s. 387) skriver: "Keeping hopes non-time-specific serves as a protective device; individuals are protected from disappointment when hope is not realized within a specific time frame."

Det er lett å tenke seg at religiøse håp kan fungere som en slik protective device mot skuffelser. Et sterkt håp om evig salighet vil kunne gjøre det lettere å forsake goder i dette livet og hindrer at man fortviler om livet skuffer en. I flere studier har man funnet at religiøse mennesker er mer håpefulle enn ikkereligiøse, og at de sjeldnere tar sitt eget liv, men ingen har påvist at det er deres håpefullhet som virker beskyttende mot selvmord (Van Ness \& Larson, 2002).

Filosofen Gabriel Marcel (2004) definerer håp som noe helt atskilt fra forventningen eller $\varnothing$ nsket om nytelse eller andre positive tilstander. Essensen av håp er ikke håpet om noe, men bare det å håpe hevder han. Stanford Encyclopedia of Philosophy (2004) gir følgende eksempel for å forklare Marcels tenkning: "If I desire that my disease be cured by a given surgical procedure, it is very possible that my desire might be thwarted. However, if I simply maintain myself in hope, no specific event (or absence of event) need shake me from this hope." Marcel fremstiller ikke dette som et håp om hinsidig lykke, men et håp knyttet til selve det å leve. Marcels idé om håp synes å tilsvare det vi her har kalt optimisme eller håpefullhet.

At optimisme kan beskytte mot selvmordsatferd indikeres av en tverrsnittsstudie (av 284 collegestudenter) som viser at personer med en mer optimistisk forklaringsstil hadde færre selvmordstanker enn personer med en mer pessimistisk forklaringsstil (Hirsch \& Conner, 2006). Mer spesifikt fant de en statistisk signifikant interaksjon mellom tendensen til å tilskrive negative hendelser til eksterne, spesifikke og forbigående faktorer (kalt optimistisk forklaringsstil) og færre selvmordstanker.

\section{Oppsummering}

I suicidologisk forskning finner vi sjelden begrepet håp. Derimot brukes det en rekke begreper som kan sees som forutsetninger for - eller konsekvenser av håp.
Eksempler er begreper knyttet til mestring (resilience - Roy et al., 2007, hardiness - Orbach et al., 1996, sense of coherence - Mehlum, 1998; Edwards \& Holden, 2001, problem solving skills - Dieserud et al., 2001; Speckens \& Hawton, 2005 positive future thinking - MacLeod et al., 2005; O'Connor et al., 2007)

- begreper knyttet til personlighetstrekk (optimism - Hirsch \& Conner, 2006 openness to experience / extroversion - Brezo et al., 2008

high self esteem - Bhar et al., 2008)

- og begreper knyttet til mål og verdier (positive life goals - Vincent et al., 2004 reasons for living - Lizardi et al., 2007).

Antagelig har man $\varnothing$ nsket mer spesifikke og målbare begreper enn begrepet håp. Håp er likevel et viktig begrep i møte med pasienter. Begrepet har en hverdagsspråklig gyldighet, og det kan sette ord på en opplevelse av at "det ble tent et nytt lys i фynene hennes", som ikke så lett lar seg redusere til noe mer spesifikt og målbart.

Begrepet håp lar seg presisere. Som en oppsummering kan håp sies å innebære at en person vil at en fremtidig tilstand skal bli virkelig, og han tror realiseringen av tilstanden er usikker, men sannsynlig. $\AA$ ville noe impliserer å $\emptyset$ nske det. $\AA$ tro det faktisk vil bli virkelig vekker glede, mens å tro at det kanskje ikke blir virkelig vekker smerte.

Smerten ved usikkerheten om tilstanden vil bli virkelig, og smerten ved skuffelsen når man innser at den $\varnothing$ nskede tilstanden ikke vil bli virkelig, har gitt skepsis til om håp er et gode. Det er flere veier til robuste håp som vekker mindre smerte. Lohnes pasienter beskrev en endring av håpets innhold gjennom indre kamp og personlig vekst. Også religiøse håp, håp uten klare frister for realisering eller med uspesifikt innhold er robuste mot skuffelser. En annen beskyttelse mot skuffelser er å ha en håpefull holdning som innebærer at man tolker inntrykk på en optimistisk måte.

Tro på at man kan medvirke til å realisere det man håper på gir motivasjon, og 
kan føre til planlegging og handling for å virkeliggjøre håpet. Mangel på slik motivasjon kan gi en opplevelse av håpløshet. Men å definere håp som det å ha en slik motivasjon, slik Snyder gjør, strider mot vår intuisjon om at man kan ha håp om at noe vil skje av seg selv eller ved andres hjelp.

Hvordan kan man vekke håp? Alt som motvirker de ulike kildene til håpløshet som er nevnt, kan bidra til å skape håp. Håp kan vekkes gjennom å se at realiseringen av noe er mulig, og enda mer om man selv kan realisere dette. $\AA$ kunne se for seg $\varnothing$ nskelige tilstander man vil realisere forutsetter minner om lignende tilstander, og hjelp til å huske slike tilstander kan vekke håp. Fordi man ikke har håp om det man tar som en selvfølge, er det paradoksalt nok slik at opplevelse av sykdom og motgang også vekker håp. En tredje tolkning av myten om Pandoras eske er derfor at håpet ble skapt i det $\varnothing$ yeblikket ulykkene slapp ut.

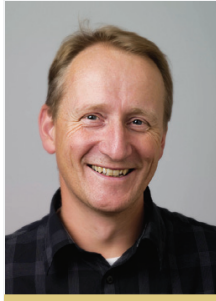

Henning Herrestad er førsteamanuensis ved Nasjonalt senter for selvmordsforskning og -forebygging.

\section{Referanser}

Beck, A. T. (1986). Hopelessness as a predictor of eventual suicide 24. Annals of the New York Academy of Sciences, 487, 90-96.

Beck, A. T., Weissman, A., Lester, D., \& Trexler L. (1974). The measurement of pessimism: the hopelessness scale 38. Journal of Consulting and Clinical Psychology, 42, 861-865.

Bhar, S., Ghahramanlou-Holloway, M., Brown, G., \& Beck, A. T. (2008). Self-esteem and suicide ideation in psychiatric outpatients. Suicide \& Life-Threatening Behavior, 38, 511-516.

Brezo, J., Paris, J., \& Turecki, G. (2006). Personality traits as correlates of suicidal ideation, suicide attempts, and suicide completions: a systematic review. Acta Psychiatrica Scandinavica, $113,180-206$.

Collins, S. \& Cutcliffe, J. R. (2003). Addressing hopelessness in people with suicidal ideation: building upon the therapeutic relationship utilizing a cognitive behavioural approach. J Psychiatr Ment Health Nurs., 10, 175-185.

Cutcliffe, J. R. \& Barker, P. (2002). Considering the care of the suicidal client and the case for 'engagement and inspiring hope' or 'observations'. J Psychiatr Ment Health Nurs., 9, 611-621.
Cutcliffe, J. R., Stevenson, C., Jackson, S., \& Smith, P. (2007). Reconnecting the person with humanity: how psychiatric nurses work with suicidal people. Crisis, 28, 207-210.

Day, J. P. (1991). Hope: A philosophical Inquiry. Acta Philosophica Fennica, 51, 1-101.

Dieserud, G., Roysamb, E., Ekeberg, O., \& Kraft, P. (2001). Toward an integrative model of suicide attempt: a cognitive psychological approach. Suicide \& Life-Threatening Behav. 31, 153-168. Dufault, K. \& Martocchio, B. C. (1985). Hope: its spheres and dimensions (Symposium on compassionate care and the dying experience). Nursing clinics of North America, 20, 379-391.

Edwards, M. J. \& Holden, R. R. (2001). Coping, meaning in life, and suicidal manifestations examining gender differences. Journal of Clinical Psychology, 57, 1517-1534.

Glanz, L. M., Haas, G. L., \& Sweeney, J. A. (1995). Assessment of Hopelessness in Suicidal Patients. Clinical Psychology Review, 15, 49-64

Grewal, P. K. \& Porter, J. E. (2007). Hope theory: a framework for understanding suicidal action. Death Studies, 31, 131-154.

Herth, K. (1992). Abbreviated instrument to measure hope: development and psychometric evaluation. J Adv Nurs., 17, 1251-1259.

Hirsch, J. K. \& Conner, K. R. (2006). Dispositional and explanatory style optimism as potential moderators of the relationship between hopelessness and suicidal ideation. Suicide \& LifeThreatening Behavior, 36, 661-669.

Lizardi, D., Currier, D., Galfalvy, H., Sher, L., Burke, A., Mann, J. et al. (2007). Perceived reasons for living at index hospitalization and future suicide attempt. Journal of Nervous \& Mental Disease, 195, 451-455.

Lohne, V. (2008). The battle between hoping and suffering: a conceptual model of hope within a context of spinal cord injury. Advances in Nursing Science, 31(3), 237-248.

MacLeod, A. K., Pankhania, B., Lee, M., \& Mitchell, D. (1997). Parasuicide, depression and the anticipation of positive and negative future experiences. Psychol. Medicine, 27, 973-977.

MacLeod, A. K., Rose, G. S., \& Williams, M. (1993). Components of hopelessness about the future in parasuicide. Cognitive Therapy and Research, 17, 441-455.

MacLeod, A. K., Tata, P., Tyrer, P., Schmidt, U., Davidson, K., \& Thompson, S. (2005). Hopelessness and positive and negative future thinking in parasuicide. Br.J.Clin.Psychol. 44, 495-504.

Marcel, G.H. (2004). Hope. I Stanford Encyclopedia of Philosophy, Stanford University. http://plato.stanford.edu/entries/marcel/\#14 (Lest 6.3.2009)

Mehlum, L. (1998). Suicidal ideation and sense of coherence in male conscripts. Acta Psychiatrica Scandinavica, 98, 487-492.
Melges, F. T. \& Bowlby, J. (1969). Types of Hopelessness in Psychopathological Process. Archives of General Psychiatry, 20, 690-699.

O'Connor, R. C., Whyte, M. C., Fraser, L., Masterton, G., Miles, J., \& MacHale, S. (2007). Predicting short-term outcome in well-being following suicidal behaviour: the conjoint effects of social perfectionism and positive future thinking. Behaviour Research \& Therapy, 45, 1543-1555.

Oquendo, M. A. \& Mann, J. J. (2000). The biology of impulsivity and suicidality. Psychiatr.Clin.North Am., 23, 11-25.

Orbach, I., Stein, D., Palgi, Y., Asherov, J., HarEven, D., \& Elizur, A. (1996). Perception of physical pain in accident and suicide attempt patients: self-preservation vs self-destruction. Journal of Psychiatric Research, 30, 307-320.

Roy, A., Sarchiapone, M., \& Carli, V. (2007).

Low resilience in suicide attempters. Archives of Suicide Research, 11, 265-269.

Rustoen, T. (2008). Endrer håpet seg med diagnoser? Omsorg - Nordisk tidsskrift for palliativ medisin, 25, 7-11.

Rustoen, T., Howie, J., Eidsmo, I., \& Moum, T. (2005). Hope in patients hospitalized with heart failure. Am. Journal of Critical Care, 14, 417-425.

Rustoen, T., Wahl, A. K., Hanestad, B. R., Gjengedal, E., \& Moum, T. (2004). Expressions of hope in cystic fibrosis patients: a comparison with the general population. Heart \& Lung, 33, 111-118.

Schrank, B., Stanghellini, G., \& Slade, M. (2008) Hope in psychiatry: a review of the literature. Acta Psychiatrica Scandinavica, 118, 421-433.

Snyder, C. R. (1994). The psychology of hope: you can get there from here. N.Y.: Free Press.

Snyder, C. R. (2000a). Handbook of hope : theory, measures \& applications. San Diego: Academic Press.

Snyder, C. R. (2000b). The past and possible futures of hope. Journal of Social \& Clinical Psychology 19[1], 11-28.

Snyder, C. R. (2002). Hope theory: Rainbows in the mind. Psychological Inquiry, 13, 249-275.

Speckens, A. E. \& Hawton, K. (2005). Social problem solving in adolescents with suicidal behavior: a systematic review. Suicide \& LifeThreatening Behavior, 35, 365-387.

Van Ness, P. H. P. \& Larson, D. B. M. (2002). Religion, senescence, and mental health: the end of life is not the end of hope. American Journal of Geriatric Psychiatry, 10, 386-397.

Vincent, P. J., Boddana, P., \& MacLeod, A. K. (2004). Positive life goals and plans in parasuicide. Clinical Psychology \& Psychother., 11, 90-99.

Williams, M. (2001). Suicide and attempted suicide: understanding the cry of pain. (2nd ed.) London: Penguin Books. 